\title{
The Enigma of Ethical Responsiveness: A Philosophical Perspective
}

\author{
Augusta Benda Hofmeyr \\ Department of Philosophy, University of Pretoria, Pretoria, South Africa \\ Email address: \\ benda.hofmeyr@up.ac.za
}

\section{To cite this article:}

Augusta Benda Hofmeyr. The Enigma of Ethical Responsiveness: A Philosophical Perspective. Humanities and Social Sciences. Special Issue: Ethical Sensitivity: A Multidisciplinary Approach. Vol. 4, No. 2-1, 2016, pp. 5-12. doi: 10.11648/j.hss.s.2016040201.12

Received: November 30, 2015; Accepted: January 15, 2016; Published: May 13, 2016

\begin{abstract}
This essay considers the enigma of ethical responsiveness from a Levinasian point of view. According to Levinas, the self is ontologically driven to persist in self-interest and therefore "naturally" inclined to consider other persons and all other forms of alterity as means to sustain itself in existence. How, then, is ethical action - which places the interest of the Other before that of the self - possible? The violent and indifferent world in which we live seems to lend credence to Levinas's contention that ethical action is an unlikely occurrence. At the same time, instances of goodness, i.e. small acts of kindness, great acts of bravery, and even lifespans of serving those in need occur on a daily basis amidst the prevailing callousness. While Levinas's ethical metaphysics offers us thought-provoking insights into the possibility of ethical responsiveness in a largely apathetic world, his thought is not to be understood as a toolkit that offers practicable guidelines that may assist agents to negotiate the quagmire of ethical dilemmas in the real world. This essay starts by offering the reader a brief overview of the three dominant schools of ethical thought that underpin the various approaches to addressing ethical decision-making in the concrete world, a world that requires decisive action. Before addressing Levinas's perspective and his invaluable contribution to this discussion, it is shown why none of these three dominant schools succeed unproblematically to provide practicable answers to ethical dilemmas.
\end{abstract}

Keywords: Ethics, Ethical Responsiveness, Ethical Responsibility, Ethical Action, Levinas

\section{Introduction}

Philosophers have contemplated the quagmire of ethical judgment since the dawn of time, testifying to the fact that even outside the murky waters of research involving persons with disabilities, there is no definitive framework that offers individuals unambigious directives on how they ought to act in every conceivable situation. Philosophers have tried (in vain) to separate the chaff from the wheat by distinguishing the theory from the practice, i.e. to distinguish the rational normative frameworks from real world situations in which the conflicting interests of persons collide. From a rationaltheoretical perspective, how one ought to act would, in the first instance, not be determined by the specific situation that you find yourself in, but by a normative framework or set of principles that have been devised on rational grounds, appropriated, and then applied when the need arises. Within this context, and by way of providing some orientation to non-philosophers, section 2 critically considers the three dominant schools of ethical thought that underpin the various approaches to addressing ethical decision-making in the concrete world (discussed in section 3): (1) virtue ethics; (2) utilitarian ethics; and (3) deontological ethics. These three schools of thought reflect the fact that ethical decisions tend to prioritize either the person or ethical agent, his/her action, or the consequences of such an action. These seemingly clearcut considerations run adrift when confronted with the fuzzy logic of ethical dilemmas. Circumstances requiring ethical decision-making more often than not entail situations in which noble motives have dire consequences, where good people acting on seemingly solid moral principles inadvertently inflict pain and suffering upon others, or inversely, where a 'good' outcome results from questionable means. In the face of these challenges, a meta-ethical perspective is considered. Sections 4 and 5 examine to what extent the philosophy of Emmanuel Levinas manages to provide insight into the nature and complexity of ethical 
decision-making and action.

\section{Three Dominant Schools of Ethics: A Brief Philosophical Primer}

\subsection{Virtue Ethics}

Virtue ethics focuses on the importance of having a good character, which is achieved to the degree to which someone is an admirable type of person rather than to the degree to which a person does the right thing or follows the right principles or rules. Virtue ethics therefore focuses on how people are (their character) as opposed to what they do or the rules they follow. This person-centred approach judges the goodness of an act - whether it is just, fair and morally justified - on the character of the actor. In the Nicomachean Ethics written by Aristotle circa 350 B. C., he distinguishes between the character of a person and his/her actions:

"Actions, then, are called just and temperate when they are such as the just or the temperate man would do; but it is not the man who does these that is just and temperate, but the man who also does them as just and temperate men do them. It is well said, then, that it is by doing just acts that the just man is produced, and by doing temperate acts the temperate man; without doing these no one would have even a prospect of becoming good" [1, Book II, §4].

A good character is therefore formed by performing good acts. If good acts precede and are responsible for honing the resultant character of the actor, one must know on what grounds acts are considered good. To ascertain the relation between good acts and good character, Aristotle turns to virtue. According to him, the soul houses three kinds of things: passions, faculties and states of character. Passions refer to appetite, anger, fear, confidence, envy, joy, hatred, longing, pity and generally all feelings accompanied by pleasure and pain. The faculties are those things by virtue of which we are capable of experiencing these feelings. States of character he defines as the position we take in relation to the passions, e.g. "with reference to anger we stand badly if we feel it violently or too weakly, and well if we feel it moderately" $[1, \S 5]$. Our passions therefore do not seem to be the root of evil, but rather our relative ability (character) to hold sway over our passions and to maintain the golden mean. For Aristotle, the golden mean is the desirable middle between two extremes, one of excess and the other of deficiency. Aristotle considers courage as a virtue, for example, but excessive courage would result in recklessness, whereas insufficient courage would simply be cowardice. Passions, according to Aristotle, are ethically neutral, i.e. neither good nor bad in their own right. Passions therefore cannot be reduced to and should not be confused with virtues or vices. We feel anger and fear without choice, often as involuntary responses to certain situations, whereas virtues and vices entail conscious decision-making [1, §5]. Aristotle further explains that what is considered as virtuous is relative and in relation to a number of factors:

"both fear and confidence and appetite and anger and pity and in general pleasure and pain may be felt both too much and too little, and in both cases not well; but to feel them at the right times, with reference to the right objects, towards the right people, with the right motive, and in the right way, is what is both intermediate and best, and this is characteristic of virtue. Similarly, with regard to actions also there is excess, defect, and the intermediate" $[1, \S 6]$.

This leads Aristotle to conclude that we are not good or bad by nature. To be sure, some things are nature-given. Take the senses, for example: "it was not by often seeing or often hearing that we got these senses, but", as Aristotle explains, "on the contrary we had them before we used them, and did not come to have them by using them" $[1, \S 1]$. The virtues, on the other hand, we acquire by first exercising them: "[f]or the things that we have to learn before we can do them, we learn by doing them, e.g. men become builders by building and lyreplayers by playing the lyre; so too we become just by doing just acts, temperate by doing temporate acts, brave by doing brave acts" $[1, \S 1]$.

From the perspective of virtue ethics, then, the character of the actor or agent is the only guarantee that the chosen course of action will be right or morally good. Within the context of research involving persons with disabilities, or biomedical ethics, for example, one would hope that the character of the researcher or the (para-)medical practitioner would be beyond reproach, and as such would certainly count for a great deal in terms of the ethical decisions taken by such individuals. However, how character is judged and the fact that "good character" would manifest differently in different individuals and result in different (ethical) decisions, point to the fact that virtue ethics is a self-driven labour of ethical self-formation, rather than a toolkit for negotiating ethical conundrums.

\subsection{Utilitarian Ethics}

Utilitarian ethics, on the other hand, focuses on the consequences of one's actions, and is frequently identified with the writings of Jeremy Bentham (1748-1832) and John Stuart Mill (1806-1873) [Cf. 2-4]. Classical Utilitarianism advocates the principle of providing "the greatest happiness to the greatest number" as the basis for assessing the morality of various actions. One should act in such a way that the consequences of your actions brings about the most good possible - the most happiness, well-being or pleasure. The ethical focus is therefore not so much on what you do, but on the outcomes of your actions, and whether or not these outcomes serve the greater good. As such, utilitarian ethics is an example of a consequentialist approach to ethical decision-making. The obvious dilemma that often arises in utilitarian contexts is whether an end is justified by the means. Is it justified, for example, to risk the lives or suffering of a few for the eventual well-being of all as in animal and/human experimentation?

Over the years utilitarianism has undergone a number of refinements, such as "act utilitarianism", "rule utilitarianism", "negative utilitarianism", and "preference utilitarianism" [2]. Act utilitarianism takes the position that, 
when facing a moral choice, one must consider the expected consequences of various potential actions and, based on this analysis, choose to do what we believe will generate the most happiness or pleasure for the most people. A rule utilitarian, by contrast, analyses an ethical dilemma by looking at potential rules of action that may be applicable, and adheres to the rule that would be expected to produce the most happiness or pleasure. Negative utilitarianism requires us to act so as to produce the least amount of evil or harm for the greatest number of people. In the case of preference utilitarianism, advocated by Peter Singer [5-6], the goal is to meet the preferences of the greatest number of people.

Singer is Professor of Bioethics at Princeton University's Center for Human Values and a profoundly influential contemporary philosopher who espouses rationalist, atheist, and utilitarian viewpoints. Because of the difficulty of measuring happiness, his approach prefers to satisfy the "preference" of those affected. A moral decision thus amounts to determining the strongest preferences of all those affected by the decision. This approach has led him to articulately challenge closely held beliefs on infanticide, euthanasia, and the moral status of animals [5, 7-9].

Two fundamental ethical precepts underpin Singer's philosophy. Firstly, one should not inflict unnecessary pain on any living thing; and secondly, the defining characteristic of a "person" is self-awareness. Singer would thus see it as ethically correct to allow the killing of unwanted neonates born with severe neurological disabilities. He would argue that they are not self-aware and therefore not persons. Since neonates can feel pain, Singer's first ethical precept dictates that this killing be done as painlessly as possible — for example, by lethal injection. He would see this as more humane than allowing death through withdrawal of care [89]. Singer advocates a "quality-of-life" ethic as a replacement for the more traditional "sanctity-of-life" framework advocated by many established moral philosophers and religious leaders. In particular, he is a proponent of a "journey model of life", which establishes the wrongness of killing by the degree to which this would frustrate a person's (not necessarily a human person's) ${ }^{1}$ life goals. He also holds that a person's right to life is fundamentally tied to that person's mental capacity to have preferences, to feel pain and to experience pleasure. As a result of this latter position, for example, Singer offers a utilitarian approach to abortion that weighs the preferences of a mother against the preferences of the fetus. Since a fetus, at least in the early weeks of pregnancy, has no capacity to think, to suffer or to hold preferences, there is nothing to weigh against a mother's preferences to undergo an abortion. ${ }^{2}$ This makes Singer see

1 Philosophical theories of personhood distinguish between humans and persons. Accordingly, not all persons are human and not all humans are persons. Personhood requires that one (ordinarily) be in possession of continuous consciousness over time and that one be capable of mental representations concerning the world, as well as able to consider options, develop tactics and act on plans.

2 It could be argued, of course, that our humanity is precisely situated in our ability and willingness to protect those who cannot fend for themselves. abortion as morally permissible.

Bioconservatives such as Leon Kass view Singer's philosophical positions as incongruous, since they are so profoundly counterintuitive. They argue that the notion of "sanctity of human life", even if only a mere intuitive notion, should triumph over all other philosophical positions in matters regarding human life. Other bioconservatives in Kass's camp argue that Singer's "absurd" conclusions follow necessarily as logical outcomes of a defective underlying moral theory, preference utilitarianism. They argue that if there is a problem with Singer's conclusions, it is entirely because of flaws inherent to preference utilitarianism, and not from flaws in Singer's logic. Deploying a variation of the ancient "reductio ad absurdum" argument (in which a proposition is disproven by following its implications to a logical but absurd consequence), they argue that since Singer's impeccable logic yields completely ridiculous results, the philosophical foundations of preference utilitarianism are thereby proven to be seriously flawed [Cf. 10-13]. So even if one replaces the problematic notion of "the greatest good" with "meeting the preferences of the greatest number of people", utilitarian approaches remain riddled with problems, not the least of which is the fact that the particular is sacrificed for "the greater good" - a "good" that often remains contentious or to be proven in due course with no immediate guarantee that "the good" will not prove a pipe dream.

\subsection{Deontological Ethics}

Deontological ethics (from the Greek word deon, meaning obligation or duty), on the other hand, bases ethics on the principles or obligations behind actions, rather than their consequences. The most famous exponent of the ethics of principle is of course German Enlightenment philosopher, Immanuel Kant (1724-1804) [Cf. 14-15]. The duties can be either positive/prescriptive (such as to care for our family) or negative/proscriptive (such as not to steal). This approach is non-consequentialist in the sense that these principles are held to be obligatory regardless of any good or bad consequences that might result. For example, it is wrong to kill even if it results in great benefit. The foundational principle of his approach is known as the categorical imperative: one should only act on a principle that everyone else could act on as well, in other words, if everyone lived by the principles that guide your actions, would the world end up being a better place? The second formula of the categorical imperative, which brings us closer to the business at hand, requires one not to use people as mere means.

Within the context of research involving people with disabilities it might be instructive to mention a deontological approach pertaining specifically to biomedical ethical dilemmas. Principlism is a commonly used approach to tackling bioethical problems in the Western world consisting of four guiding principles propounded by the so-called "Georgetown School" of bioethics. These are:

(1) respect for autonomy, i.e. the right to actively 
participate in medical decisions concerning oneself without being dictated to or controlled by other parties. This principle obviously comes under pressure when dealing with persons who cannot clearly express or articulate their right to selfdetermination. In such cases, (para-)medical practitioners base their decisions on appropriate course of action on principle 2 :

(2) beneficence, i.e. the requirement that caregivers, all else being equal, should do what they can to improve the patient's situation. While (para-)medical practitioners might be able to agree on what constitutes an improvement of the patient's situation, in practice it often conflicts with the patient's right to selfdetermination.

(3) The third principle is non-malfeasance, i.e. the requirement to avoid bringing harm to the patient, a seemingly indubitable principle, which nevertheless comes into question when "quality of life" is considered more important than the "right to life", as argued by Peter Singer.

(4) Finally, the principle of justice requires the fair and impartial treatment of all persons, especially in the context of resource allocation. In practice, resources are invariably limited and more so in certain contexts, which necessitates (para-)medical practitioners to make judgments often on utilitarian grounds on who is "more deserving" of the resources [16].

These principles are intentionally content thin to make them more broadly applicable within the field of practical dilemmas, but as such they more often rely on human judgment, which result in giving preference to certain principles at the expense of others. Beauchamp and Childress present them as prima facie rather than absolute obligations, i.e. based on the first impression and as such accepted as correct until proved otherwise [16]. Given their generality and overridability, Beauchamp and Childress hold that implementing their view requires, among other things, appropriately specifying and balancing these principles by reference to the particular circumstances of a situation. They have been critiqued by Clouser and Gert, who argue that these principles fail to function as claimed, and that their use is misleading both practically and theoretically [17]. The principles are in fact not guides to action, but function as mere names for a collection of sometimes superficially related matters for consideration when dealing with a moral problem. As seen above, the principles lack any systematic relationship to each other, and often even conflict with each other. Clouser and Gert maintain that these conflicts are unresolvable, since there is no unified moral theory from which they are all derived.

\section{Tripartite Structure of Ethical Judgment}

The three dominant ethical schools of thought, virtue ethics, utilitarian ethics and deontological ethics therefore focus on the person, the outcome and the action respectively as normative locus for ethical decision-making. In other words, these normative frameworks serve as a directive for making rational decisions concerning actions deemed right or good within particular situations. Their respective foci are not accidental, but reflects the tripartite structure of ethical judgment:

(1) an appropriated or internalized normative framework (or principles, which form the locus of deontological approaches), which enables

(2) the rational weighing of better and worse courses of actions in a specific situation (the internalized norms along with the consistency with which these are applied speak to the character of the person, which is the locus of virtue ethics) based on

(3) the estimated impact of this action (which utilitarian approaches take as decisive for ethical decision making).

What makes ethical judgment or decision-making so thorny is the fact that none of these three components are ever unambigiously clear, and their interrelatedness invariably complicates things when it sometimes happens that they are relatively clear. In reality, they are locked in an interlinked cross-contaminating loop: instead of offering us three solid pillars that form a foolproof foundation for sound ethical judgment, the loop forms a downward spiral. As a result, ethical decision-making is more often than not precisely the prima facie assessment of the relative importance of the three in relation to each other, involving value judgments or consensus rulings. Plainly put, in the face of conflicting considerations and limited resources (the limitation of time, of means, of human capacity and rational ability to choose wisely amongst competing imperatives), we often end up going with our gut, resorting to common sense or intuition to decide the undecidable. The simple fact is that real-life situations invariably prove these normative frameworks to be inadequate and ineffective.

It is at this juncture that I want to turn to the philosophy of Emmanuel Levinas, a $20^{\text {th }} \mathrm{C}$ French-Jewish thinker whose "ethical metaphysics" is dedicated to come to grips with the conditions of possibility of ethical action. For Levinas, ethical action consists in placing the needs of the other person before that of the self. As such, ethical action is an unlikely - perhaps even "unnatural" occurrence - since we are naturally inclined or ontologically programmed, if you will, to be concerned with ourselves first and foremost. By our very being, we are preoccupied with our own continued existence, which he describes as the drive to persist in existence and to care for the self. Levinas fundamentally challenges the self-centred logic of ontology. In response, the locus of his work is on the inherent responsibility we bear for the other person. For Levinas, however, this "principle" is not a rational normative principle, but an affectedness, quite simply a "feeling" that literally moves us, so much so that we can no longer remain indifferent to the need or the plight of the other person we feel addressed by. 


\section{Ethics as an Exclusively Social Phenomenon: Levinas on the Self and the Other}

Despite its brevity, the schematic outline provided thus far confirms the undeniable social character of ethics. Whether one uses character, consequences or the call of duty as criterion for ethical decision-making and action, a social context is necessarily implied. Actions that occur in a vacuum do not fall within the purview of ethics, unlike actions that directly or indirectly impact upon others and upon the world in which we live collectively. An ethical relationship per definition involves $a$ self, the agent of ethical action, and the other, i.e. the person, sentient being or object upon which such action impacts. Within the context of research involving persons with disabilities, the focus would be on the relationship between the agent or researcher and its object(s). When research is conducted, the object of study is subjected to the reductive analytical gaze of an agent, who, in respect to his/her object and concerning the relevant condition or abilities, is more able or 'valid'. This kind of inequality in expertise and abilities is a necessary condition, if you will, within the context of research. The object of study therefore finds him/herself in a particularly vulnerable position risking exactly the kind of reduction to mere means that Kant warns us against.

The ethical metaphysics of Levinas throws a further spanner in the works of this tripartite equation: according to him, we cannot begin to fathom the other person (distinguished from other forms of alterity that the self encounters in the world as "the Other") and consequently the impact of our actions upon that Other. Moreover, ethical initiative is not, contrary to the dominant schools of ethical thought, the self's prerogative vested in the rational weighing of better or worse options. Rather, the possibility of ethical action proceeds from the self following an infinitely more fundamental address encountered when faced by another person in need. The absolute Other - which for Levinas is epitomized by the other person - precisely subverts any attempt on our part to establish a rational relationship with that Other. Absolute alterity incarnated in the person of another is quite literally "inconceivable". We cannot begin to know or understand that which in its very essence defies objectification. The Other is always, and per definition, more than our perception or understanding of him/her. The relation between the self and the Other, in Levinasian terms, is a nonrelation, a relation without relation. Hereby Levinas is attempting to express the fundamental contradiction of human relatedness: as persons we are fundamentally connected as fraternity, which means that we cannot not be affected by the plight of the other person. We are affected by virtue of the fact that the Other shows him-/herself as "face" or expression, Yet, this "epiphany" cannot be reduced to a fathomable "form" with recognizable features. The Other resonates with something in the self that cannot be conceived in terms of rational categories. As such, the Other remains fundamentally alien to me.

Yet, this absolute stranger does not leave me cold; it is impossible to remain unaffected by a close encounter with a vulnerable other. The Other affects me in the most fundamental way possible; the other cuts to the very core of my being. This affectedness by the Other is not something that can be rationally accounted for. It is also not an ethical imperative. Rather it is an ontological fact inscribed into the very being of us humans. What is at the heart of humanity, according to Levinas, is the fact that we are beings capable of being affected by the fate of another human being, to the extent that this concern overrides any concern for self. Levinas explains it as follows: "[t]he tie with the Other is knotted only as responsibility, this moreover, whether accepted or refused, whether knowing or not knowing how to assume it, whether able or unable to do something concrete for the Other. To say: here I am [me voici] ... To be human spirit, that's it" [18, p97]. Contrary to the history of modern conceptions of rational subjectivity that situates the uniqueness of the human self in its capacity for rational autonomy, Levinas contends that what makes us truly human is precisely the irrational ability to be affected by that which cannot be grasped rationally. Prior to the sovereignty or the self-legislating "nature" of the individual, is an affectedness by another - a heteronomy - that which throws our autonomy in disarray. We shall return to this enigmatic contention shortly.

This notion of a fundamental affectedness by the plight of others flies in the face of countless testimonies borne by this cruel world. One needs only to switch on the television or radio, or cast a cursory glance at newspaper headings to know that we live in a world rampant with hatred, discrimination, disrespect, and worst of all, indifference. This uniquely human capacity to feel - or at least not to be left cold by - the need, pain or suffering of the Other is sadly not a guarantee for ethical action. Despite not being able not to feel the appeal emanating from the face of the Other in dire straits, one remains free to act on or ignore the call. Ethical action, according to Levinas, is a return from the preconscious being affected -which is not a rational weighing of possible courses of action - precisely to the conscious world of rational decision-making. In other words, ethical action becomes possible because we are ineluctably affected by the Other, but this is a necessary not a sufficient condition. Apart from feeling responsible, action requires a decisive choice to act in response to this feeling. The question of ethical action will be discussed at greater length in section 5 .

According to Levinas, this responsibility is infinite. I am responsible not just for what I have done to the Other. My responsibility is not limited to being held accountable for my own actions. According to Levinas [18, p99], "I am responsible even for the Other's responsibility". I am responsible even for what other others have done to the Other. This responsibility is very much $m y$ responsibility since it extends to one's very right to existence - a right that impinges upon the rights of others. The fact that I am thriving 
is directly or indirectly the result of violence done to the Other. Here one only has to think of the violence imposed by colonialism, by Apartheid, by neo-liberal capitalism, by all the dominant exploitative forces that have secured a place in the sun for some at the expense of others. For Levinas, the notion of responsibility that is necessarily mine is tied to the notion of substitution. Levinas defines substitution as follows:

"To substitute oneself does not amount to putting oneself in the place of the other man in order to feel what he feels; it does not involve becoming the other nor, if he be destitute and desperate, the courage of such a trial. Rather, substitution entails bringing comfort by associating ourselves with the essential weakness and finitude of the other; it is to bear his weight while sacrificing one's interestedness and complacency-in-being, which then turn into responsibility for the other" [19, p228].

The face of the vulnerable Other therefore confronts us with an indictment that surpasses our human capacities to respond in an adequate manner. For how can I possibly "bring comfort" or "bear the weight" of the world, a weight so grave that it is certain to crush me. According to Levinas, then, by virtue of existing we are always already guilty and without adequate resources to make amends.

What would be the point then of engaging with Levinas on the issue of ethics especially within the realm of research involving persons with disabilities, a field already overburdened with ethical difficulties and dilemmas? Should we then not rather keep to principles, or to ethical rationalizations of the greater good, or rely on the good character or conscience of the researcher to provide us with some practicable directives? After all, these issues pertain to care-givers and (para-)medical practitioners who are in the business of rendering a service, of action - a context which renders philosophical ponderings a luxury that only those in the ivory tower can afford.

\section{From Radical Passivity to the Possibility of Ethical Action}

How we ought to act, the ethical question par excellence, is according to Levinas, fundamentally not a question of action, not in the first instance anyway. Instead, he speaks of "radical passivity": passivity as the radix (Latin for 'root') of ethical action. The non-relation with the appealing Other is indeed remedial and didactic, but it is not the resourceful, capable self that teaches or aids the vulnerable Other. Rather, it is the proximity of the disempowered, the disenfranchised, the disabled, that puts my power, my capacity, my commandment of the world in question. For the first time, and time and time again when faced with such vulnerability, I am struck by the violence of my rational, calculated egotistical engagement with all things other: I see only what I am looking for, and reduce the Other to the limited confines of a preconceived conceptual framework. To be sure, Levinas is not simply inverting the relationship between self and the
Other. He is trying to get to the very heart of ethics: where to find the resources for goodness in a world that shows little if any evidence of its existence?

Goodness precisely is not of this world, according to Levinas. It comes from elsewhere, from beyond the parameters of our customary human engagements with the world. Yet, instances of goodness - small acts of kindness, great acts of bravery, and even lifespans of self-sacrifice dot the history of humankind like stars light the night sky. The possibility of goodness arises when I am overcome by an encounter with a face that stops me in my tracks, that inverts my critical interrogative gaze, robs me of any rationalizations or clever calculations. I am brought face to face with the fact that my very being is in essence reductive and disrespectful: our customary way of dealing with what is foreign, is to reduce it to fit our existing frames of meaning giving reference.

How to proceed from here? How to actualize the potential of true ethical action introduced by the paralysing indictment of the face the Other? If self-preservation and egotism is inscribed in my very being, how do I do the impossible, that which is not inscribed but imposed from without? According to Levinas, the face-to-face encounter with the Other has an inward impact that puts me in touch with something that has always already been there, but that can only be activated from without, however. The interested reader is directed to Levinas's distinction between "transascendence" and "transdescendence" eloquently explained in Burggraeve [20] and Hofmeyr [21-23]. According to Descartes, a finite being can only think the Infinite, because the Infinite has put the idea of Infinity within the finite [Cf. 24, p47-59; 25, p75-76]. Similarly, the limited, egotistical self can only do the good if the idea of goodness has been placed within it by the Good. The very self-interested nature of our being has always already been infected by the possibility - a predisposition, if you will - to suppress this self-interest and be dis-interested. Disinterest is not indifference, but precisely interest in the Other, for the sake of the Other without any personal gain selflessness. The Good, for Levinas, is beyond our daily runof-the-mill being in the world, but we nevertheless carry the trace of Goodness within - an affectedness, feeling or gut instinct that overrides the slippery slope of rational calculations of what is better or worse in a particular situation.

\section{Conclusion}

When faced with ethical dilemmas, what ought we to do then? The three dominant schools of ethical thought discussed in sections 2 and 3 above, have proven only deceptively instructive. These guidelines or moral principles often fall short in providing unambigiously clear instructions in concrete situations. Levinas's ethical metaphysics has likewise been criticized for not offering any concrete practicable directives that provide guidance through the mare's nest of ethical decision-making. Some critics are even scathingly critical of Levinasian 'ethical responsibility': "it 
consists in nothing but an empty caricature of a self responding without comprehension to an equally empty command that it could not know how to obey issuing from another person incoherently described" [26, p54]. In fact, his thought is not to be understood as an "ethical theory" that is somehow better than virtue ethics, utilitarian or deontological approaches to ethical dilemmas. Instead, Levinas's thought takes a step back from the world of decision-making and action, and tries to get to the very meaning of ethics. How is it even possible to act ethically - to place the well-being of the Other before our own - if our very being is ontologically defined by self-interest, the drive to survive and persist in this existence for our own sake? The attentive reader will find that Levinas does not in fact prescribe anything, but simply discovers that our self-interest is always-already troubled by an inherent responsibility for the Other. We tend to silence this call of conscience - an inherent feeling of disquiet that signals the fact that the distress of the Other indicts my prosperity, my affluence, my good fortune. True, Levinas fails to tell us what to do. This is not his project, for he would certainly not presume to prescribe a course of action in response to a responsibility that is precisely $m y$ responsibility, uniquely mine, a cross that no one can bear in my stead. Perhaps the moral of his story is precisely that we have done enough - enough damage, enough violence, enough good intentions and well-meant interventions. Perhaps it is time to be still. To do nothing but be attentive. To allow ourselves to be taught, to let the Other be heard. Perhaps the most fundamental human disability in need of our attention is not physical or mental, but precisely our ethical impairment. To truly hear the Other and to act accordingly is to become deaf to what $I$ think is best for the Other. Levinas therefore displaces the ethical locus from the rational self's sovereign decision-making power to a subservience to the teachings of the Other's need. This requires a willingness on the part of the self to open itself up and allow itself to be affected by the plight of another. To feel the pain of another may not simplify ethical decision-making, but it will ensure that such decisions are taken with the sincerity and gravity befitting of situations in which the fate or well-being of another is at stake.

\section{References}

[1] Aristotle. Nicomachean Ethics, trans. Roger Crisp. Cambridge: Cambridge University Press; 2000.

[2] Gillon, R. "Utilitarianism", in British Medical Journal (Clinical Research Edition). 1985; 290: 1411-1413. PubMed PMID: 3922515; PubMed Central PMCID: PMC1415603.

[3] Dolan, P. "Utilitarianism and the Measurement and Aggregation of Quality-Adjusted Life years", in Health Care Anal. 2001; 9 (1): 65-76. PubMed PMID: 11372576.

[4] Gandjour, A. \& Lauterbach, K. W. "Utilitarian Theories Reconsidered: Common Misconceptions, More Recent Developments, and Health Policy Implications", in Health Care Anal. 2003; (3): 229-44. PubMed PMID: 14708935.
[5] Jamieson, D. Singer and His Critics. Malden, MA: Blackwell; 1999.

[6] Singer, P. A. The Life You Can Save: Acting Now to End World Poverty. New York, NY: Random House.; 2009.

[7] Singer, P. A. Animal Liberation. New York: Harper Collins; 1975.

[8] Singer, P. A. Rethinking Life and Death: The Collapse of Our Traditional Values. New York: St. Martin's Griffin; 1995.

[9] Singer, P. A. Practical Ethics. Second Edition. Cambridge, UK: Cambridge University Press; 2011.

[10] Kass, L. R. "The Wisdom of Repugnance", in The New Republic. 1997; 216: 17-26. (Online: http://www.people.umass.edu/jaklocks/Phil164/kass.doc).

[11] Howard, J. "The Moral Status of the Human Embryo According to Peter Singer: Individuality, Humanity, and Personhood", in Linacre Q. 2005; 72(3): 212-28. PubMed PMID: 16317845.

[12] Roache, R. \& Clarke, S. "Bioconservatism, Bioliberalism, and the Wisdom of Reflecting on Repugnance, in Monash Bioethical Review. 2009; 28 (1): 4.1-21. PubMed PMID: 19839275.

[13] Doyle, D. J. "Should Logic Trump Intuition in Bioethical Discourse? Contrasting Peter Singer and Leon Kass", in Ethics in Biology, Engineering and Medicine. 2011; 2: 1-9.

[14] Kant, I. Grundlegung zur Metaphysik der Sitten/Groundwork of the Metaphysics of Morals, reference to the Academie edition, trans. Paton, H. J. The Moral Law. London: Hutchinson; 1948.

[15] Kant, I. Die Metaphysik der Sitten/Metaphysics of Morals (published separately as Doctrine of Right and the Doctrine of Virtue), trans. Gregor, M. Philadelphia: University of Pennsylvania Press; 1964.

[16] Beauchamp, T. \& Childress, J. Principles of Biomedical Ethics. Oxford: Oxford University Press; 2001.

[17] Clouser, K. D. \& Gert, B. "A Critique of Principlism", in Journal of Medical Philosophy. 1990; 15(2): 219-236. doi: 10.1093/jmp/15.2.219

[18] Levinas, E. Ethics and Infinity. Conversations with Philippe Nemo, trans. Richard A. Cohen. Pittsburg, Pennsylvania: Duquesne University Press; 1985.

[19] Levinas, E. Is it Righteous To Be? Interviews with Emmanuel Levinas, ed. Jill Robbins. Stanford: Stanford University Press; 2001.

[20] Burggraeve, R. "Affected by the Face of the Other. The Levinasian Movement from the Exteriority to the Interiority of the Infinite", in Dialegesthai. Rivista telematica di filosofia. 2009; $11 . \quad$ Available online: http://mondodomani.org/dialegesthai/ ISSN 1128-5478 Accessed 30 November 2015.

[21] Hofmeyr, A. B. (Ed.) Radical Passivity. Rethinking Ethical Agency in Levinas. Dordrecht, NL: Springer. Book Series: Library of Ethics and Applied Philosophy; 2009. ISBN: 978$1-4020-9346-3$

[22] Hofmeyr, A. B. "Radical Passivity: Ethical Problem or Solution?", in Hofmeyr, A. B. (Ed.) 2009: 25-49. 
[23] Hofmeyr, A. B. "From Activity to Radical Passivity: Rethinking Ethical Agency in Levinas", in Monokl. 2010; 8-9: 97-117.

[24] Levinas, E. Collected Philosophical Papers, trans. Alphonso Lingis. Pittsburg, Pennsylvania: Duquesne University Press; 1987.

\section{Biography}

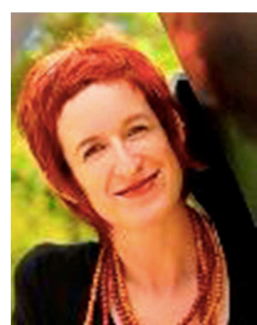

Benda Hofmeyr is currently affiliated to the Department of Philosophy, University of Pretoria, South Africa. Her research interests fall within the broad ambit of contemporary Continental philosophy (especially thinkers following in the wake of Heidegger with emphasis on post-structuralism and phenomenology) with an enduring fascination for the inextricable entanglement of the ethical and the political. At present, she is reflecting on the entanglement of European and non-Western, especially post-colonial African philosophy and the possibility of a dialogue across these divergent yet fundamentally intertwined traditions of thought. For more information: benda.hofmeyr@up.ac.za and/or www.bendahofmeyr.com
25] Levinas, E. Alterity and Transcendence, trans. Michael B. Smith. New York: Columbia University Press; 1999.

[26] Hutchens, B. C. Levinas. A Guide for the Perplexed. New York: Continuum; 2004. 